\title{
RESEARCH
}

Open Access

\section{$A \beta$ misfolding in blood plasma is inversely associated with body mass index even in middle adulthood}

Tobias Möllers ${ }^{1,2^{*}}$ D, Hannah Stocker ${ }^{1,2,3}$, Laura Perna ${ }^{1,4}$, Andreas Nabers ${ }^{5,6}$, Dan Rujescu', Annette M. Hartmann ${ }^{7}$, Bernd Holleczek ${ }^{8}$, Ben Schöttker ${ }^{1,2}$, Klaus Gerwert ${ }^{5,6}$ and Hermann Brenner ${ }^{1,2}$

\begin{abstract}
Background: To understand the potential for early intervention and prevention measures in Alzheimer's disease, the association between risk factors and early pathological change needs to be assessed. Hence, the aim of this study was to determine whether risk factors of Alzheimer's clinical syndrome (clinical AD), such as body mass index $(B M I)$, are associated with $A \beta$ misfolding in blood, a strong risk marker for $A D$ among older adults.

Methods: Information on risk factors and blood samples were collected at baseline in the ESTHER study, a population-based cohort study of older adults (age 50-75 years) in Germany. A 3 misfolding in blood plasma was analyzed using an immuno-infrared-sensor in a total of 872 participants in a nested case-control design among incident dementia cases and matched controls. Associations between risk factors and A $\beta$ misfolding were assessed by multiple logistic regression. For comparison, the association between the risk factors and AD incidence during 17 years of follow-up was investigated in parallel among 5987 cohort participants.

Results: An inverse association with $A \beta$ misfolding was seen for BMl at age 50 based on reported weight history (aOR $0.64,95 \% \mathrm{Cl} 0.43-0.96, p=0.03$ ). Similar but not statistically significant associations were seen for $\mathrm{BMI}$ at baseline (i.e., mean age 68) and at age 40 . No statistically significant associations with $A \beta$ misfolding were found for other risk factors, such as diabetes, smoking, and physical activity. On the other hand, low physical activity was associated with a significantly reduced risk of developing clinical AD compared to physical inactivity.

Conclusions: Our results support that AD pathology may be detectable and associated with reduced weight even in middle adulthood, many years before clinical diagnosis of AD. Physical activity might reduce the risk of onset of AD symptoms.
\end{abstract}

Keywords: Alzheimer's disease, Amyloid beta misfolding, BMI, cohort study

\footnotetext{
* Correspondence: t.moellers@dkfz-heidelberg.de

'Division of Clinical Epidemiology and Aging Research, German Cancer Research Center, Im Neuenheimer Feld 581, Heidelberg, Germany

${ }^{2}$ Network Aging Research, Heidelberg University, Bergheimer Straße 20, Heidelberg, Germany

Full list of author information is available at the end of the article
}

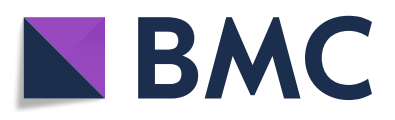

(- The Author(s). 2021 Open Access This article is licensed under a Creative Commons Attribution 4.0 International License, which permits use, sharing, adaptation, distribution and reproduction in any medium or format, as long as you give appropriate credit to the original author(s) and the source, provide a link to the Creative Commons licence, and indicate if changes were made. The images or other third party material in this article are included in the article's Creative Commons licence, unless indicated otherwise in a credit line to the material. If material is not included in the article's Creative Commons licence and your intended use is not permitted by statutory regulation or exceeds the permitted use, you will need to obtain permission directly from the copyright holder. To view a copy of this licence, visit http://creativecommons.org/licenses/by/4.0/ The Creative Commons Public Domain Dedication waiver (http://creativecommons.org/publicdomain/zero/1.0/) applies to the data made available in this article, unless otherwise stated in a credit line to the data. 


\section{Background}

The development of Alzheimer's disease (AD) is characterized by early pathological change, specifically amyloid beta $(A \beta)$ deposits and tau tangles in the brain, followed by dementia symptoms, which may occur 15 to 20 years after the initial onset of the disease [1]. Considering the biological construct of $\mathrm{AD}$, it is particularly important to assess the associations of modifiable risk factors with markers of early pathological change.

One aspect of pathological change in AD includes the structural changes of the $A \beta$ peptide, in which its folds are altered from healthy monomeric predominantly disordered or partly $\alpha$-helical to pathological $\beta$-sheetenriched secondary structures [2]. This is also known as misfolding. Once $\beta$-sheet-enriched structures aggregate, they can form soluble toxic oligomers and macroscopically visible amyloid plaques, which are thought to contribute to $\mathrm{AD}$ neurodegeneration $[3,4]$. The process of misfolding causes a shift in the overall secondary structure distribution within the total $A \beta$ fraction in cerebrospinal fluid (CSF) and blood plasma. Structural misfolding of $A \beta$ in blood plasma can be measured by an immuno-infrared-sensor (iRS) $[5,6]$. In previous studies, we have shown that $A \beta$ misfolding in blood plasma is correlated to CSF AD biomarkers and amyloid PET imaging and is highly predictive of Alzheimer's clinical syndrome (clinical AD) many years before clinical diagnosis [6-8]. Most recently, we were able to show that $\mathrm{A} \beta$ misfolding in blood plasma might be an early risk marker of AD that is independent of age [9].

The relationship between common risk factors of clinical $A D$, such as physical activity or body mass index (BMI), and $A \beta$ misfolding in blood plasma remains unknown to date. A particularly interesting risk factor is obesity. There have been discussions about the "obesityparadox" where late-life obesity is associated with a lower risk of developing clinical $\mathrm{AD}$ as well as studies reporting an association of higher late-life BMI with lower $\mathrm{A} \beta$ burden $[10,11]$.

Therefore, the aim of this study was to assess the association of BMI and other common clinical AD risk factors with $A \beta$ misfolding within a community-based cohort study of older adults. The associations between these risk factors and the incidence of clinical AD were investigated in parallel for comparison.

\section{Materials and methods}

\section{Study design and population}

The study population consists of participants of the ongoing population-based prospective ESTHER cohort study (Epidemiologische Studie zu Chancen der Verhütung Früherkennung und optimierten Therapie chronischer Erkrankungen in der älteren Bevölkerung) [6, 12, 13]. People aged 50-75 years attending a general health examination were recruited by their general practitioners (GPs) in a statewide study in Saarland, Germany, from 2000 to 2002. Standardized self-administered health questionnaires were filled out by participants, who also provided blood samples, including heparin plasma samples (stored at $-80^{\circ} \mathrm{C}$ ). The GPs provided further medical information and comprehensive follow-ups were conducted through participants and GP questionnaires $2,5,8,11,14$, and 17 years after recruitment. Information on vital status and causes of death was obtained from population registries and local health authorities. The ESTHER study was approved by the Ethics Committee of the Medical Faculty of Heidelberg University and the Physicians' Board of Saarland.

At baseline, 9940 participants were included in the ESTHER study. In a nested case-control approach, $A \beta$ misfolding was measured in blood plasma among cases with a GP reported diagnosis of dementia up to the 14-year follow-up and controls without dementia (i.e., absence of any dementia diagnosis as specified by the participants' physicians) diagnosis that were matched to the cases by sex, age, and education as previously described [6]. Our main analysis is based on 872 participants $(n=167$ dementia cases, $n=705$ participants without dementia diagnosis) in whom measurements of $A \beta$ misfolding were performed.

For comparison, we conducted a secondary analysis including 5987 participants with available information regarding $\mathrm{AD}$ diagnosis or confirmed lack of dementia diagnosis at the 17-year follow-up (Fig. 1). Information on clinical $\mathrm{AD}$ diagnosis was provided by the participants' GPs during the 14- and 17-year follow-ups as previously reported [13]. In short, GPs were asked to fill out questionnaires regarding any dementia diagnosis and type of dementia of the participants and provide all available medical records from specialists such as neurologists or psychiatrists. The National Institute on Aging and the Alzheimer's Association or the International Working group-2 criteria are recommended for clinical AD diagnosis in Germany [14-16].

\section{Biomarkers and risk factors}

The blood plasma samples used in this study were collected at baseline and $A \beta$ misfolding was assessed as previously reported $[6,7]$. Briefly, soluble $A \beta$ peptides were extracted from blood plasma, which was acquired, processed, and frozen at baseline, and alterations in the $A \beta$ peptide secondary structure distribution were measured for each participant with an immuno-infrared-sensor (WO 2015121339 A1), whose details also have been reported elsewhere $[5,6,17]$. In agreement with the previously validated spectral threshold, participants with a cutoff of $<1642 \mathrm{~cm}^{-1}$ were considered to have increased A $\beta$ misfolding [6]. 


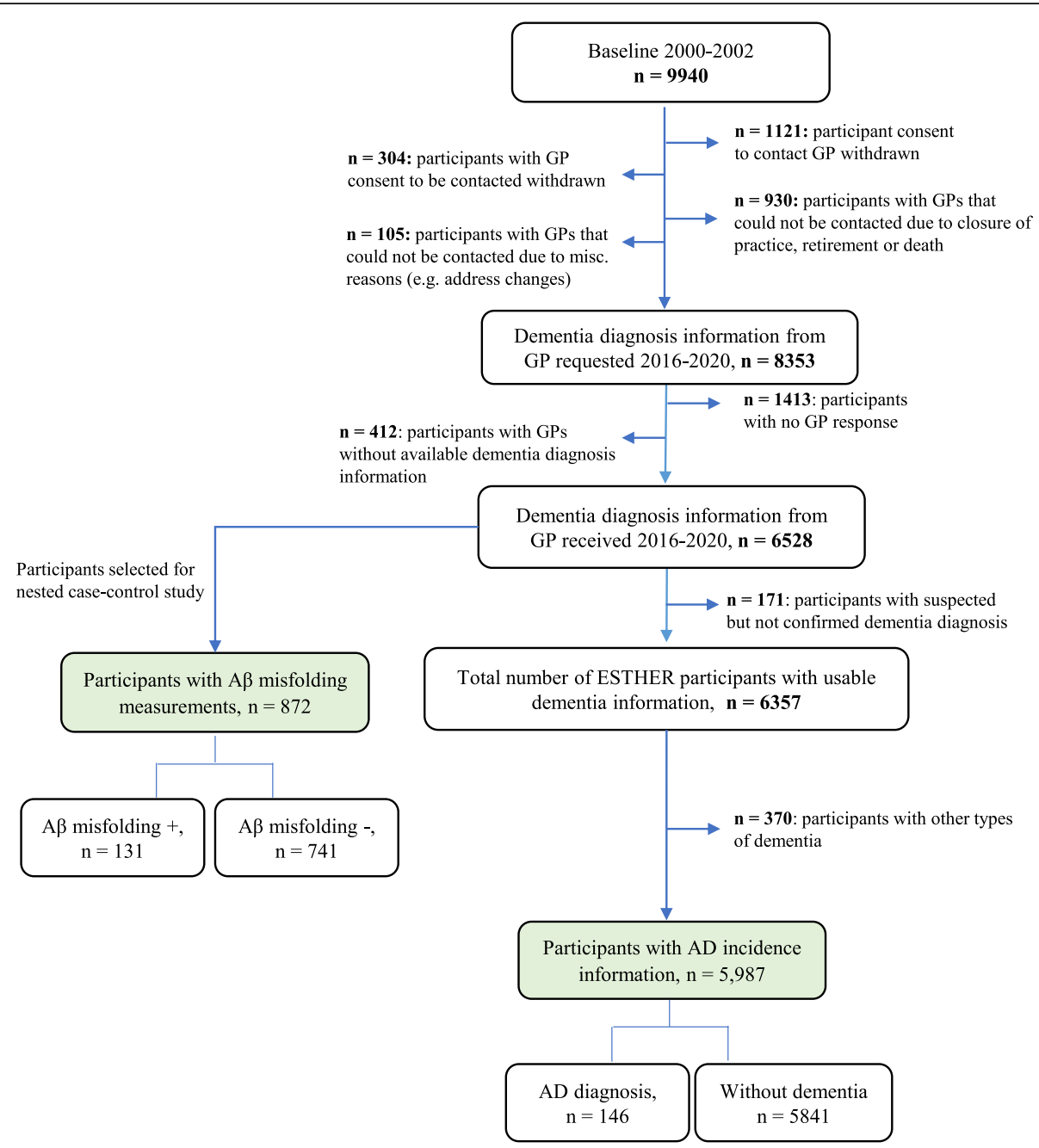

Fig. 1 Participants from the ESTHER prospective cohort study included in analyses

APOE genotyping was performed using Taqman SNP genotyping assays with genotypes analyzed in an endpoint allelic discrimination read using a PRISM 7000 Sequence detection system (Applied Biosystems, Foster City, CA). Participants with $\geq 1 A P O E \varepsilon 4$ allele were considered $A P O E \& 4$ positive ( $A P O E \varepsilon 4+$ ).

Additional risk factors ascertained at baseline included age, sex, educational level, smoking (never, former, current), physical activity (inactive $<1 \mathrm{~h}$ of physical activity/week, low $\geq 1 \mathrm{~h}$ of physical activity/week but $<2 \mathrm{~h}$ of vigorous and $<2 \mathrm{~h}$ of light physical activity/week, medium/high $\geq 2 \mathrm{~h}$ of light and $\geq 2 \mathrm{~h}$ of vigorous physical activity/week), diabetes (physician diagnosis or use of glucose-lowering drugs), and body mass index (BMI). BMI was based on self-reported measurements of height and weight because this was the more complete assessment at baseline. Height and weight were also measured by the GPs during the health check-up and the measurements had very high agreement with the selfreported information: $95.8 \%$ for height within $\pm 5 \mathrm{~cm}$ range and $96.5 \%$ for weight within $\pm 5 \mathrm{~kg}$ range. In addition, BMI calculated from retrospectively reported weights at the age of 50 and 40 years was considered. Based on the limited number of participants in the underweight and obesity groups, BMI was considered dichotomously as $<25.0$ (underweight/normal weight) and $\geq 25.0 \mathrm{~kg} / \mathrm{m}^{2}$ (overweight/obesity) as well as continuously per $5 \mathrm{~kg} / \mathrm{m}^{2}$.

In addition to single risk factors, a previously established 34-item frailty index (FI) based on the accumulation of deficits approach, with items including comorbidities (e.g., heart failure, stroke), self-rated health, difficulties in activities of daily living, and the presence of symptoms such as insomnia, was utilized [18]. Considered variables had to be associated with health status, accumulate with age, do not saturate too 
early, have more than $1 \%$ prevalence, and should cover a range of health problems and disabilities. This frailty index quantifies frailty as the ratio of present deficits divided by the total number of deficits considered. Cutoff points distinguishing frail and non-frail participants were derived by assessing the 10-year mortality risk with 9 pre-defined cutoff points. Non-significant strata were combined, and the following cutoff points were established: FI 0 to $\leq 0.20$ for non-frail, FI 0.21 to $<0.45$ for pre-frail, and FI $\geq 0.45$ for frail participants, respectively [18].

\section{Statistical methods}

This study included two analyses: (1) the main crosssectional analysis investigating the association between $\mathrm{BMI}$ and other modifiable risk factors of clinical AD with $\mathrm{A} \beta$ misfolding measured in blood plasma and (2), for comparison, a longitudinal analysis investigating the association between the abovementioned risk factors and incidence of clinical AD within 17 years of follow-up. The adjusted analysis included all variables mentioned in the risk factors section above.

In the cross-sectional analysis, $A P O E \& 4$ had the highest percentage of missing values (13.4\%). Hence, multiple imputation for data missing at random with thirteen imputations was done using the Markov chain Monte Carlo method utilizing all variables listed in Tables 1 and 2 including $A \beta$ misfolding status [19]. Multiple logistic regression utilizing the imputed datasets, with $A \beta$ misfolding status as the dependent variable, was used to calculate odds ratios (OR) with 95\% confidence intervals (CI). The adjusted analysis included all variables mentioned in the risk factors section above.

In the secondary analysis, $A P O E \varepsilon 4$ had the highest percentage of missing values as well (11.6\%). Accordingly, multiple imputation for data missing at random with twelve imputations was done using the Markov chain Monte Carlo method utilizing all variables listed in Tables 1 and 2 including AD status [19]. Cox proportional hazards regression utilizing the imputed datasets was used to calculate hazard ratios (HRs) including 95\% CIs with the incidence of clinical $\mathrm{AD}$ diagnosis as the dependent variable. The censoring dates for these analyses included the date of $\mathrm{AD}$ diagnosis, date of death, date of drop out, or date of the 17-year follow-up (date of response from the GP regarding dementia diagnosis status).

Multicollinearity in multivariable models was examined (and found to be of no concern) by the tolerance, variation inflation factor, eigenvalue, and condition index. Participant characteristics were compared utilizing $t$-tests for continuous and chi-square tests for categorical variables. Statistical difference was defined by $p$ values $<0.05$ in two-sided testing. All analyses were conducted using SAS software, version 9.4 (SAS Institute, Cary, NC).

\section{Results \\ Sample characteristics}

Details regarding the participant characteristics and a flowchart outlining the sample derivation are presented in Table 1 and Fig. 1.

In the main analysis, 872 participants with available $A \beta$ misfolding measurement were included, of whom 131 (15\%) were considered to have increased $A \beta$ misfolding. In terms of age, sex, education, and diabetes, the participants with increased and normal $A \beta$ misfolding were fairly similar. $A P O E \& 4$ allele presence was more prevalent in participants with increased $A \beta$ misfolding. A lower percentage of participants with increased $A \beta$ misfolding had a BMI $\geq 25 \mathrm{~kg} / \mathrm{m}^{2}$ at baseline than participants with normal $\mathrm{A} \beta$ misfolding.

In the secondary analysis, a total of 5987 participants with available information on clinical AD status were included, of whom 146 (2.4\%) had a diagnosis of AD. On average, participants who were diagnosed with clinical $\mathrm{AD}$ during follow-up were older than participants who remained dementia-free (66.7 vs. 61.3). Incident $A D$ cases were also more commonly female and less educated than those without AD diagnosis (61\% vs. $55 \%$ and $82.4 \%$ vs. $7.3 \%$, respectively). Physical inactivity (33.6\% vs. $18.2 \%)$ and frailty $(15.2 \%$ vs. $46.7 \%)$ at baseline were more common among participants with a later diagnosis of $\mathrm{AD}$ as well.

\section{Association of $B M I$ with $A \beta$ misfolding and clinical $A D$}

Figure 2 shows that the mean BMI rose from age 40 to age 50 to baseline among participants included in the cross-sectional and longitudinal analysis. The lower BMI among participants with increased compared to normal $\mathrm{A} \beta$ misfolding was much more pronounced than the lower BMI of participants with clinical AD compared to participants without dementia diagnosis. In fact, Table S1 (Suppl. Material) shows that there were no significant differences in mean BMI values for $\mathrm{AD}$ cases compared to dementia-free participants at baseline, at the age of 50 or at the age of 40 . The mean BMI values were significantly lower for participants with increased $A \beta$ misfolding than for participants with normal $\mathrm{A} \beta$ misfolding at each time point (baseline, 27.1 vs. 28.0; age 50, 25.1 vs. 26.0; age $40,24.0$ vs. $25.6 \mathrm{~kg} / \mathrm{m}^{2}$ ) (Fig. 2).

Associations of BMI with $A \beta$ misfolding and clinical $\mathrm{AD}$ adjusted for all covariates shown in Table 1 are presented in Table 2. Interestingly, there was an association of BMI values with $A \beta$ misfolding at different time points. In detail, an increase of BMI per $5 \mathrm{~kg} / \mathrm{m}^{2}$ at age 50 was associated with a significantly reduced odds of having increased $A \beta$ misfolding at baseline (OR per 5 
Table 1 Participant characteristics of the nested case-control study within ESTHER and of ESTHER participants with confirmed Alzheimer's disease status at the 17-year follow-up

\begin{tabular}{|c|c|c|c|c|c|}
\hline \multirow{2}{*}{\multicolumn{2}{|c|}{ Characteristics at baseline }} & \multicolumn{2}{|c|}{$\begin{array}{l}\text { Nested case-control study within } \\
\text { ESTHER }\end{array}$} & \multicolumn{2}{|c|}{$\begin{array}{l}\text { ESTHER participants with confirmed AD status from the } 17 \text {-year follow- } \\
\text { up }\end{array}$} \\
\hline & & \multirow{2}{*}{$\begin{array}{l}\mathrm{A} \beta \text { misfolding+ } \\
\boldsymbol{n}(\%) \\
131(15.0)\end{array}$} & \multirow{2}{*}{$\begin{array}{l}\begin{array}{l}\text { A } \beta \text { misfolding- } \\
\boldsymbol{n}(\%)\end{array} \\
741(85.0)\end{array}$} & \multirow{2}{*}{$\begin{array}{l}\text { Alzheimer's disease diagnosis } \\
\boldsymbol{n}(\%) \\
146(2.4)\end{array}$} & \multirow{2}{*}{$\begin{array}{l}\text { Participants without dementia diagnosis } \\
\boldsymbol{n}(\%) \\
5841 \text { (97.6) }\end{array}$} \\
\hline Total & & & & & \\
\hline \multirow[t]{4}{*}{ Age } & Mean \pm SD & $68.3 \pm 4.9$ & $68.5 \pm 4.7$ & $66.7 \pm 5.1$ & $61.3 \pm 6.5^{* * *}$ \\
\hline & $50-64$ & $27(20.6)$ & $137(18.5)$ & $48(32.9)$ & $3902(66.8)^{* * *}$ \\
\hline & $65-69$ & $39(29.8)$ & $236(31.9)$ & $45(30.8)$ & $1259(21.6)^{* * *}$ \\
\hline & $70-75$ & $65(49.6)$ & $368(49.7)$ & $53(36.3)$ & $680(11.6)^{* * *}$ \\
\hline \multirow[t]{2}{*}{ Sex } & Female & $68(51.9)$ & $435(58.7)$ & $89(61.0)$ & $3184(54.5)$ \\
\hline & Male & $63(48.1)$ & $306(41.3)$ & $57(39.0)$ & $2657(45.5)$ \\
\hline \multirow[t]{2}{*}{ Education } & $\leq 9 \mathrm{yrs}$ & $115(87.8)$ & $645(88.2)$ & $117(82.4)$ & $4154(72.7)^{*}$ \\
\hline & $\geq 10 \mathrm{yrs}$ & $16(12.2)$ & 86 (11.8) & $25(17.6)$ & $1561(27.3)^{*}$ \\
\hline \multirow[t]{2}{*}{ APOE $\varepsilon 4+$} & No & $81(66.9)$ & $484(74.7)$ & $64(50.0)$ & $3926(75.0)^{* * *}$ \\
\hline & Yes & $40(33.1)$ & $164(25.3)$ & $64(50.0)$ & $1309(25.0)^{* * *}$ \\
\hline \multirow[t]{2}{*}{ Diabetes } & No & $100(76.3)$ & $586(79.1)$ & $116(79.5)$ & $4950(85.7)^{*}$ \\
\hline & Yes & $31(23.7)$ & 155 (20.9) & $30(20.6)$ & $825(14.3)^{*}$ \\
\hline \multirow[t]{3}{*}{ Physical activity } & Inactive & $35(26.7)$ & $243(32.8)$ & 49 (33.6) & $1061(18.2)^{* * *}$ \\
\hline & Low & 68 (51.9) & 352 (47.6) & $57(39.0)$ & $2648(45.4)^{* * *}$ \\
\hline & Medium/high & $28(21.4)$ & 145 (19.6) & $40(27.4)$ & $2118(36.4)^{* * *}$ \\
\hline \multirow[t]{3}{*}{ BMl } & Mean \pm SD & $27.1 \pm 3.8$ & $28.0 \pm 4.2^{* *}$ & $27.2 \pm 3.9$ & $27.7 \pm 4.5$ \\
\hline & $<25$ & 37 (29.1) & $171(23.8)$ & 45 (31.5) & $1612(28.1)$ \\
\hline & $\geq 25$ & 90 (70.9) & $548(76.2)$ & $98(68.5)$ & 4127 (71.9) \\
\hline \multirow[t]{3}{*}{ Smoking } & Never & $66(50.8)$ & $396(55.7)$ & $83(58.9)$ & 2891 (50.6) \\
\hline & Former & $47(36.2)$ & 234 (32.9) & $42(29.8)$ & 1933 (33.8) \\
\hline & Current & $17(11.4)$ & 81 (11.4) & 16 (11.4) & 892 (15.6) \\
\hline \multirow[t]{4}{*}{ Frailty Index } & Mean \pm SD & $0.3 \pm 0.1$ & $0.3 \pm 0.2$ & $0.3 \pm 0.2$ & $0.2 \pm 0.1^{* * *}$ \\
\hline & $\begin{array}{l}\text { Non-frail } \\
0 \text { to } \leq 0.20\end{array}$ & $31(34.4)$ & 175 (39.7) & 39 (39.4) & $2298(53.3)^{* *}$ \\
\hline & $\begin{array}{l}\text { Pre-frail } \\
>0.20 \text { to }<0.45\end{array}$ & $50(55.6)$ & $203(46.0)$ & $45(45.5)$ & $1697(39.4)^{* *}$ \\
\hline & $\begin{array}{l}\text { Frail } \\
\geq 0.45\end{array}$ & $9(10.0)$ & $63(14.3)$ & $15(15.2)$ & $315(7.3)^{* *}$ \\
\hline
\end{tabular}

$\mathrm{kg} / \mathrm{m}^{2}$ 0.64, 95\% CI 0.43-0.96). Additionally, similar inverse associations were apparent for BMI per $5 \mathrm{~kg} / \mathrm{m}^{2}$ at baseline and at age 40 and baseline $A \beta$ misfolding $\left(O R_{B L}\right.$ per $5 \mathrm{~kg} / \mathrm{m}^{2} 0.73$, 95\% CI $0.52-1.03 ; \mathrm{OR}_{40}$ per $5 \mathrm{~kg} / \mathrm{m}^{2}$ 0.80, 95\% CI 0.54-1.19), which did though not reach statistical significance. In comparison, with the exception of a BMI of $\geq 25 \mathrm{~kg} / \mathrm{m}^{2}$ at baseline (HR 0.66, 95\% CI 0.43-1.00), there was no significant association between $\mathrm{BMI}$ at age 40 or age 50 and clinical AD.

\section{Association of other risk factors with $A \beta$ misfolding and clinical AD}

The association of the remaining modifiable risk factors with $\mathrm{A} \beta$ misfolding and clinical AD is presented in Table 3. There was no significant association between diabetes, physical activity, smoking, and frailty index with $A \beta$ misfolding. On the other hand, physical activity and frailty status were significantly associated with clinical AD incidence. More precisely, participants with low physical 
Table 2 Distribution of BMI at different time points and its association with A $\beta$ misfolding and clinical Alzheimer's disease

\begin{tabular}{|c|c|c|c|c|c|c|c|c|c|}
\hline \multirow{2}{*}{\multicolumn{2}{|c|}{ Time point }} & \multicolumn{4}{|c|}{$A \beta$ misfolding } & \multicolumn{4}{|c|}{ Clinical Alzheimer's disease } \\
\hline & & $\begin{array}{l}N_{\text {total }} \\
\text { (col \%) }\end{array}$ & $\begin{array}{l}N_{\text {Abeta+ }} \\
\text { (row \%) }\end{array}$ & $\begin{array}{l}\text { OR }(95 \% \mathrm{Cl}) \\
\text { Adjusted }^{\mathrm{a}}\end{array}$ & $\begin{array}{l}p- \\
\text { value }^{b}\end{array}$ & $\begin{array}{l}N_{\text {total }} \\
\text { (col \%) }\end{array}$ & $\begin{array}{l}N_{\mathrm{AD}} \\
\text { (row \%) }\end{array}$ & $\begin{array}{l}\text { HR (95\% CI) } \\
\text { Adjusted }^{c}\end{array}$ & $\begin{array}{l}p- \\
\text { value }^{\mathrm{t}}\end{array}$ \\
\hline \multirow{4}{*}{ Baseline } & & & & & & & & & \\
\hline & & & & & & & & & \\
\hline & $\geq 25 \mathrm{~kg} / \mathrm{m}^{2}$ & $638(75.4)$ & $90(14.1)$ & $0.82(0.49-1.36)$ & .4385 & $4225(71.8)$ & $98(2.3)$ & $0.66(0.43-1.00)$ & .0501 \\
\hline & Per $5 \mathrm{~kg} / \mathrm{m}^{2}$ & $846(100)$ & $127(15.0)$ & $0.73(0.52-1.03)$ & .0705 & $5882(100)$ & $143(2.4)$ & $0.88(0.67-1.16)$ & .3736 \\
\hline \multirow[t]{3}{*}{ At age 50} & $<25 \mathrm{~kg} / \mathrm{m}^{2}$ & 335 (42.8) & 59 (17.6) & Ref. & & 2341 (41.3) & $62(2.7)$ & Ref. & \\
\hline & $\geq 25 \mathrm{~kg} / \mathrm{m}^{2}$ & $448(57.2)$ & $61(13.6)$ & $0.88(0.54-1.41)$ & .5817 & $3327(58.7)$ & $73(2.2)$ & $0.81(0.54-1.21)$ & .3048 \\
\hline & Per $5 \mathrm{~kg} / \mathrm{m}^{2}$ & $783(100)$ & $120(15.3)$ & $0.64(0.43-0.96)$ & .0314 & $5668(100)$ & $135(2.4)$ & $1.13(0.83-1.53)$ & .4455 \\
\hline \multirow[t]{3}{*}{ At age 40} & $<25 \mathrm{~kg} / \mathrm{m}^{2}$ & $468(61.9)$ & $74(15.8)$ & Ref. & & $3269(58.3)$ & $76(2.3)$ & Ref. & \\
\hline & $\geq 25 \mathrm{~kg} / \mathrm{m}^{2}$ & $288(38.1)$ & $38(13.2)$ & $0.87(0.53-1.42)$ & .5760 & $2340(41.7)$ & $49(2.1)$ & $1.08(0.72-1.62)$ & .7101 \\
\hline & Per $5 \mathrm{~kg} / \mathrm{m}^{2}$ & $756(100)$ & $112(14.8)$ & $0.80(0.54-1.19)$ & .2704 & $5609(100)$ & $125(2.2)$ & $1.13(0.81-1.56)$ & .4753 \\
\hline
\end{tabular}

${ }^{a}$ Adjusted for all variables listed in Table 1 and case/control status

${ }^{\mathrm{b}} p$-value derived from multiple logistic regression for adjusted odds ratios

${ }^{c}$ Adjusted for all variables listed in Table 1

activity had a reduced risk of developing clinical AD within 17 years of follow-up by $43 \%$ (HR 0.57, 95\% CI 0.39-0.85) compared to participants being physically inactive. Medium to high physical activity was nearly significantly associated with a reduced risk of clinical $\mathrm{AD}$ (HR 0.64, 95\% CI 0.41-1.01). Being frail at baseline was associated with a more than doubled risk of developing $\mathrm{AD}$ (HR 2.02, 1.10-3.95), while no significant increase in the risk of clinical AD (HR 1.11, 0.71-1.72) was observed for being pre-frail compared to not being frail.

\section{Discussion}

This study focusing on the association between risk factors for $A \beta$ misfolding in blood and AD found the presence of increased $A \beta$ misfolding to be inversely associated with lower BMI at both baseline (mean age 68 years) and at age 50 . The remaining risk factors for clinical $A D$ were not significantly associated with $A \beta$ misfolding.

\section{Association of risk factors with $A \beta$ misfolding}

The inverse association of the presence of increased $A \beta$ misfolding with lower BMI even as early as at age 50 is a novel and potentially clinically highly relevant finding of our study. Higher late-life BMI has been reported to be associated with lower $A \beta$ pathology by various studies $[11,20]$, and there have been suggestions that this association might reflect reverse causation rather than BMI effects $[10,21]$. It has been concluded that weight loss might be an intrinsic pathological feature of $A \beta$ accumulation where dementia-associated weight loss begins prior to clinical symptoms [22-24]. Furthermore, weight loss has been associated with AD CSF and imaging biomarkers in healthy elderly subjects [25]. Lower BMI in
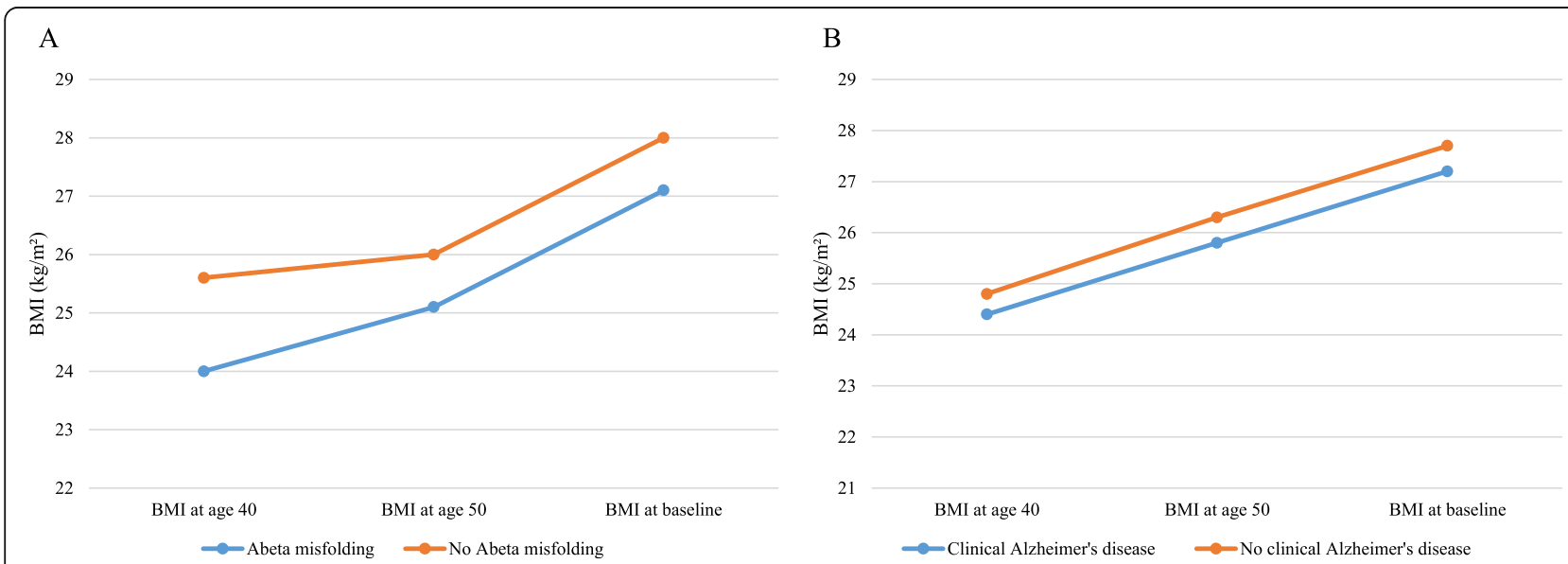

Fig. 2 Comparison of mean BMI at different time points between participants with Abeta misfolding and no Abeta misfolding $(\mathbf{A})$ and clinical Alzheimer's disease and no clinical Alzheimer's disease $(\mathbf{B})$, respectively 
Table 3 Distribution of participant characteristics and their association with A $\beta$ misfolding and clinical Alzheimer's disease

\begin{tabular}{|c|c|c|c|c|c|c|c|c|c|}
\hline \multirow{2}{*}{\multicolumn{2}{|c|}{ Characteristic at baseline }} & \multicolumn{4}{|c|}{$A \beta$ misfolding } & \multicolumn{4}{|c|}{ clinical Alzheimer's disease } \\
\hline & & \multirow{2}{*}{$\begin{array}{l}\begin{array}{l}N_{\text {total }} \\
\text { (col \%) }\end{array} \\
686(78.7)\end{array}$} & \multirow{2}{*}{$\begin{array}{l}\begin{array}{l}N_{\text {Abeta+ }} \\
\text { (row \%) }\end{array} \\
100(14.6)\end{array}$} & \multirow{2}{*}{$\begin{array}{l}\text { OR }(95 \% \mathrm{Cl}) \\
\text { Adjusted }^{\mathrm{a}} \\
\text { Ref. }\end{array}$} & \multirow{2}{*}{$\begin{array}{l}p- \\
\text { value }^{b}\end{array}$} & \multirow{2}{*}{$\begin{array}{l}\begin{array}{l}N_{\text {total }} \\
\text { (col \%) }\end{array} \\
5066(85.6) \\
\end{array}$} & \multirow{2}{*}{$\begin{array}{l}\begin{array}{l}N_{\mathrm{AD}} \\
\text { (row \%) }\end{array} \\
116(2.3)\end{array}$} & \multirow{2}{*}{$\begin{array}{l}\text { OR }(95 \% \mathrm{Cl}) \\
\text { Adjusted }^{\mathrm{c}} \\
\text { Ref. }\end{array}$} & \multirow{2}{*}{$\begin{array}{l}p- \\
\text { value }^{b}\end{array}$} \\
\hline \multirow[t]{2}{*}{ Diabetes } & No & & & & & & & & \\
\hline & Yes & $186(21.3)$ & $31(16.7)$ & $1.02(0.59-1.77)$ & .9357 & $855(14.4)$ & $30(3.5)$ & $1.10(0.65-1.87)$ & .7144 \\
\hline \multirow[t]{3}{*}{ Physical activity } & Inactive & $278(31.9)$ & 35 (12.6) & Ref. & & $1110(18.6)$ & $49(4.4)$ & Ref. & \\
\hline & Low & $420(48.2)$ & $68(16.2)$ & $1.44(0.82-2.53)$ & .2088 & $2705(45.3)$ & $57(2.1)$ & $0.57(0.39-0.85)$ & .0056 \\
\hline & Medium/high & $173(19.9)$ & $28(16.2)$ & $1.14(0.58-2.25)$ & .6978 & $2158(36.1)$ & $40(1.9)$ & $0.64(0.41-1.01)$ & .0548 \\
\hline \multirow[t]{3}{*}{ Smoking } & Never & $462(54.9)$ & $66(14.3)$ & Ref. & & $2974(50.8)$ & $83(2.8)$ & Ref. & \\
\hline & Former & $281(33.4)$ & $47(16.7)$ & $1.07(0.61-1.87)$ & .8103 & 1975 (33.7) & $42(2.1)$ & $0.89(0.59-1.35)$ & .5957 \\
\hline & Current & $98(11.7)$ & $17(17.4)$ & $1.19(0.57-2.47)$ & .6452 & $908(15.5)$ & $16(1.8)$ & $1.07(0.61-1.86)$ & .8212 \\
\hline \multirow[t]{3}{*}{ Frailty index } & $\begin{array}{l}\text { Non-frail } \\
0 \text { to } \leq 0.20\end{array}$ & $206(38.8)$ & $31(15.1)$ & Ref. & & 2337 (53.0) & $39(1.7)$ & Ref. & \\
\hline & $\begin{array}{l}\text { Pre-frail } \\
>0.20 \text { to }<0.45\end{array}$ & $253(47.7)$ & 50 (19.8) & $1.14(0.68-1.91)$ & .6132 & 1742 (39.5) & $45(2.6)$ & $1.11(0.71-1.72)$ & .6468 \\
\hline & $\begin{array}{l}\text { Frail } \\
\geq 0.45\end{array}$ & 72 (13.6) & $9(12.5)$ & $0.75(0.35-1.58)$ & .6452 & $330(7.5)$ & $15(4.6)$ & $2.02(1.10-3.95)$ & .0275 \\
\hline
\end{tabular}

${ }^{a}$ Adjusted for all variables listed in Table 1 and case/control status

${ }^{\mathrm{b}} p$-value derived from multiple logistic regression for adjusted odds ratios

${ }^{c}$ Adjusted for all variables listed in Table 1

late life has been associated with greater cortical amyloid burden among clinically normal elderly [26]. On the other hand, higher midlife BMI has been shown to be associated with a higher risk of dementia [27] and cerebral amyloid deposition, although the association was not statistically significant in cognitively normal participants [28]. Furthermore, studies showed an association of midlife obesity with AD-pattern neurodegeneration but not amyloid deposition [29]; with earlier onset of $\mathrm{AD}$; and with greater neuropathologic burden, including Braak neurofibrillary tangles [30]. Against this background, one could speculate that midlife obesity might be involved in the development of AD by pathways different from amyloid misfolding, such as vascular effects in the onset of $\mathrm{AD}$ and development of symptoms. All things considered, this result might reflect an association of unintentional weight loss (or reduced weight gain) with increased $\mathrm{A} \beta$ misfolding manifesting already in middle adulthood. This may be a very early sign of beginning $\mathrm{AD}$ pathology, particularly $\mathrm{A} \beta$ misfolding in blood. It cannot be ruled out that participants already showed unintentional weight loss as a symptom of early dementia but they had not yet received a diagnosis of dementia, which might not occur until a later stage when patients are unable to perform daily functions. It has also to be noted that this is the first study examining the relationship between $\mathrm{BMI}$ and $\mathrm{A} \beta$ misfolding. The longitudinal relationship between BMI and $A \beta$ misfolding needs further evaluation in an ideally larger sample. In addition, collecting further blood biomarkers such as inflammatory cytokines and markers of oxidative stress could contribute to entangling this relationship as these have been linked to metabolic risk factors, including significant interactions towards cognitive decline [31,32].

With regard to other common risk factors for clinical $\mathrm{AD}$ such as diabetes, physical activity, smoking, and frailty, we did not observe a significant association with increased $A \beta$ misfolding. However, the longitudinal relationship of said factors with $A \beta$ misfolding remains to be investigated.

\section{Association of risk factors with clinical AD}

In the secondary analysis, the aforementioned risk factors and their association with clinical AD incidence were assessed. The main finding of this analysis was that low physical activity was associated with a reduced risk of developing clinical AD. The association of medium/ high physical activity with reduced risk of developing clinical AD barely missed statistical significance, which was likely a result of the lack of power in that group. This is in line with previous research suggesting a benefit of physical activity on cognitive function and reduced incidence of $\mathrm{AD}[33,34]$. In consideration of the finding that physical activity was not associated with $A \beta$ misfolding, this might elude to a role of physical activity in reducing the onset of clinical symptoms rather than the prevention of Alzheimer's pathology. This is supported by a meta-analysis which found that even the cognitive function of AD patients can be improved by physical activity [35]. Additionally, participants who were classified as frail at baseline had a significantly higher risk of developing clinical $\mathrm{AD}$. The association of frailty with 
clinical AD and the close connection between the two, including shared risk factors, has been well documented [36].

\section{Strengths and limitations}

Limitations of this study include the limited power to detect weak-to-moderate associations, despite the overall large size of the cohort. In addition, the cross-sectional approach taken in the main part of the analysis precludes any conclusion about temporality or causality of associations. Regarding BMI, we relied on self-reported height and weight for all time points, which could have resulted in some misclassification. Due to the nature of a community-based cohort study, which portrays common practice rather than clinical evaluation in a highly specialized academic setting, misdiagnosis/underdiagnosis of clinical AD cannot be ruled out.

Strengths of this study include the population-based design, with data reflecting common general care practice in community settings, the use of an innovative test for measuring $\mathrm{A} \beta$ misfolding in blood, and the first-time assessment of the relationships between BMI and further modifiable risk factors of $A D$ and $A \beta$ misfolding in blood many years prior to clinical manifestation of AD.

\section{Conclusion}

This study found $A \beta$ misfolding, a very strong early marker of AD risk, not to be significantly associated with many risk factors of clinical AD. An exception was BMI, which was inversely associated with $A \beta$ misfolding even as early as at age 50 , a pattern that is consistent with AD-related weight loss (or reduced weight gain) that may be present many years before AD manifestation. $\mathrm{Fu}-$ ture studies with larger sample sizes should investigate the longitudinal relationship between modifiable risk factors and this early risk marker of AD for intervention and prevention measures.

\section{Abbreviations \\ AD: Alzheimer's disease; A : Amyloid beta; BMl: Body mass index; Cl: Confidence interval; CSF: Cerebrospinal fluid; ESTHER: Epidemiologische Studie zu Chancen der Verhütung Früherkennung und optimierten Therapie chronischer Erkrankungen in der älteren Bevölkerung; FI: Frailty index; GP: General practitioner; HR: Hazard ratio; iRS: Immuno-infrared-sensor; OR: Odds ratio}

\section{Supplementary Information}

The online version contains supplementary material available at https://doi. org/10.1186/s13195-021-00889-2.

Additional file 1: Table S1. BMI measurements at different time-points according to $A \beta$ misfolding and clinical Alzheimer's disease status.

\section{Authors' contributions}

$T M, L P, H S$, and HB made substantial contributions to the concept and design, interpreting data, and drafting the manuscript. AN performed the immuno-infrared analyses. TM carried out epidemiological analyses. BS contributed to the coordination of the ESTHER study. LP, BS, BH, DR, and HB contributed to the data acquisition for the ESTHER study. LP and AMH contributed to the interpretation of data. KG conceived the immuno-infraredsensor for secondary structure analysis of protein misfolding. HB conceived and led the ESTHER study. All authors revised the manuscript for important intellectual content and approved the final manuscript.

\section{Funding}

The ESTHER study was supported by grants from the Baden-Württemberg Ministry of Science, Research and Arts; the German Federal Ministry of Education and Research; the German Federal Ministry of Family, Senior Citizens, Women and Youth; the Saarland Ministry of Social Affairs, Health, Women and Family; and the Network Aging Research at Heidelberg University. The funding sources had no role in the study design; in the collection, analysis, and interpretation of the data; in the writing of the report; and in the decision to submit the article for publication. Open Access funding enabled and organized by Projekt DEAL.

\section{Availability of data and materials}

The datasets used and/or analyzed during the current study are available from the corresponding author on reasonable request.

\section{Declarations}

\section{Ethics approval and consent to participate}

The ESTHER study was approved by the Ethics Committee of the Medical Faculty of Heidelberg University and the Physicians' Board of Saarland. Written informed consent was obtained from each participant.

Consent for publication

Not applicable.

\section{Competing interests}

The secondary structure-based, $A \beta$ misfolding marker measured by the iRS is protected by one approved patent (EP3324187B1) and three patent applications (WO 2015121339 A1, WO 2018091743 A1, and WO 2018219969 A1) by KG and AN.

\section{Author details}

${ }^{1}$ Division of Clinical Epidemiology and Aging Research, German Cancer Research Center, Im Neuenheimer Feld 581, Heidelberg, Germany. ${ }^{2}$ Network Aging Research, Heidelberg University, Bergheimer Straße 20, Heidelberg, Germany. ${ }^{3}$ Medical Faculty, Heidelberg University, Im Neuenheimer Feld 572, Heidelberg, Germany. ${ }^{4}$ Department of Translational Research in Psychiatry, Max Planck Institute of Psychiatry, Kraepelinstraße 2-10, München, Germany. ${ }^{5}$ Department of Biophysics, Ruhr-University Bochum, Universitätsstraße 150, Bochum, Germany. ${ }^{6}$ Department of Biophysics, Center for Protein Diagnostics (ProDi), Biospectroscopy, Ruhr-University Bochum, Universitätsstraße 150, Bochum, Germany. 'University Clinic and Outpatient Clinic for Psychiatry, Psychotherapy and Psychosomatics, Martin-Luther-University Halle-Wittenberg, Julius-Kühn-Straße 7, Halle (Saale), Germany. ${ }^{8}$ Saarland Cancer Registry, Präsident-Baltz-Straße 5, Saarbrücken, Germany.

Received: 17 February 2021 Accepted: 13 August 2021

Published online: 30 August 2021

\section{References}

1. Jack CR Jr, Bennett DA, Blennow K, Carrillo MC, Dunn B, Haeberlein SB, et al. NIA-AA research framework: toward a biological definition of Alzheimer's disease. Alzheimer's Dementia. 2018;14(4):535-62.

2. Sarroukh R, Cerf E, Derclaye S, Dufrene YF, Goormaghtigh E, Ruysschaert JM, et al. Transformation of amyloid beta(1-40) oligomers into fibrils is characterized by a major change in secondary structure. Cell Mol Life Sci. 2011;68(8):1429-38. https://doi.org/10.1007/s00018-010-0529-x.

3. Cavallucci V, D'Amelio M, Cecconi F. Abeta toxicity in Alzheimer's disease. Mol Neurobiol. 2012;45(2):366-78. https://doi.org/10.1007/s12035-012-82 $51-3$. 
4. Haass C, Selkoe DJ. Soluble protein oligomers in neurodegeneration: lessons from the Alzheimer's amyloid beta-peptide. Nat Rev Mol Cell Biol. 2007;8(2): 101-12. https://doi.org/10.1038/nrm2101.

5. Nabers A, Ollesch J, Schartner J, Kotting C, Genius J, Hafermann H, et al Amyloid-beta-secondary structure distribution in cerebrospinal fluid and blood measured by an immuno-infrared-sensor: a biomarker candidate for Alzheimer's disease. Anal Chem. 2016;88(5):2755-62. https://doi.org/10.1 021/acs.analchem.5b04286.

6. Nabers A, Perna L, Lange J, Mons U, Schartner J, Guldenhaupt J, et al. Amyloid blood biomarker detects Alzheimer's disease. EMBO Mol Med. 2018;10(5):e8763. https://doi.org/10.15252/emmm.201708763.

7. S Stocker H, Nabers A, Perna L, Mollers T, Rujescu D, Hartmann A, et al. Prediction of Alzheimer's disease diagnosis within 14 years through Abeta misfolding in blood plasma compared to APOE4 status, and other risk factors. Alzheimer's Dement. 2020;16(2):283-91.

8. Stockmann J, Verberk IMW, Timmesfeld N, Denz R, Budde B, Lange-Leifhelm $J$, et al. Amyloid- $\beta$ misfolding as a plasma biomarker indicates risk for future clinical Alzheimer's disease in individuals with subjective cognitive decline. Alzheimers Res Ther. 2020;12(1):169. https://doi.org/10.1186/s13195-02000738-8.

9. Möllers $T$, Stocker $H$, Perna L, Nabers A, Rujescu D, Hartmann A, et al. A misfolding in blood plasma measured by immuno-infrared-sensor as an age-independent risk marker of Alzheimer's disease. Alzheimer's Dement. 2021;13(1):e12151. https://doi.org/10.1002/dad2.12151.

10. Pegueroles J, Jiménez A, Vilaplana E, Montal V, Carmona-Iragui M, Pané A, et al. Obesity and Alzheimer's disease, does the obesity paradox really exist? A magnetic resonance imaging study. Oncotarget. 2018;9(78):34691-8. https://doi.org/10.18632/oncotarget.26162.

11. Thirunavu V, McCullough A, Su Y, Flores S, Dincer A, Morris JC, et al. Higher body mass index is associated with lower cortical amyloid- $\beta$ burden in cognitively normal individuals in late-life. J Alzheimers Dis. 2019;69(3):81727. https://doi.org/10.3233/JAD-190154.

12. Löw M, Stegmaier C, Ziegler H, Rothenbacher D, Brenner H. Epidemiological investigations of the chances of preventing, recognizing early and optimally treating chronic diseases in an elderly population (ESTHER study). Dtsch Med Wochenschr (1946). 2004;129(49):2643-7.

13. Stocker H, Perna L, Weigl K, Möllers T, Schöttker B, Thomsen H, et al. Prediction of clinical diagnosis of Alzheimer's disease, vascular, mixed, and all-cause dementia by a polygenic risk score and APOE status in a community-based cohort prospectively followed over 17 years. Mol Psychiatry. 2020. https://doi.org/10.1038/s41380-020-0764-y.

14. Dubois B, Feldman HH, Jacova C, Hampel H, Molinuevo JL, Blennow K, et al. Advancing research diagnostic criteria for Alzheimer's disease: the IWG-2 criteria. Lancet Neurol. 2014;13(6):614-29. https://doi.org/10.1016/S14 74-4422(14)70090-0.

15. German Society for Psychiary, Psychotherapie, Psychosomatics and Neurology, German Society for Neurology, Deutschen Alzheimer Gesellschaft e.V. - Selbsthilfe Demenz. S3-Leitline "Demenzen" (Langversion) https://www.awmf.org/uploads/tx_szleitlinien/013|_S3-Demenzen-2016-07. pdf. Accessed 1 Feb 2021.

16. McKhann GM, Knopman DS, Chertkow H, Hyman BT, Jack CR Jr, Kawas CH, et al. The diagnosis of dementia due to Alzheimer's disease: recommendations from the National Institute on Aging-Alzheimer's Association workgroups on diagnostic guidelines for Alzheimer's disease. Alzheimer's Dement. 2011;7(3):263-9. https://doi.org/10.1016/j.jalz.2011.03. 005.

17. Nabers A, Hafermann H, Wiltfang J, Gerwert K. A $\beta$ and tau structure-based biomarkers for a blood- and CSF-based two-step recruitment strategy to identify patients with dementia due to Alzheimer's disease. Alzheimer's Dement. 2019;11:257-63.

18. Saum KU, Dieffenbach AK, Muller H, Holleczek B, Hauer K, Brenner H. Frailty prevalence and 10-year survival in community-dwelling older adults: results from the ESTHER cohort study. Eur J Epidemiol. 2014;29(3):171-9. https:// doi.org/10.1007/s10654-014-9891-6.

19. Schafer JL. Analysis of incomplete multivariate data: CRC press; 1997. https://doi.org/10.1201/9781439821862

20. Vidoni ED, Townley RA, Honea RA, Burns JM. Alzheimer disease biomarkers are associated with body mass index. Neurology. 2011;77(21):1913-20. https://doi.org/10.1212/WNL.0b013e318238eec1.

21. Tolppanen AM, Ngandu T, Kareholt I, Laatikainen T, Rusanen M, Soininen $H$, et al. Midlife and late-life body mass index and late-life dementia: results from a prospective population-based cohort. J Alzheimers Dis. 2014;38(1): 201-9. https://doi.org/10.3233/JAD-130698.

22. Stewart R, Masaki $K$, Xue Q, Peila R, Petrovitch $H$, White LR, et al. A 32-year prospective study of change in body weight and incident dementia. Arch Neurol. 2005;62(1):55-60. https://doi.org/10.1001/archneur.62.1.55.

23. Rabin JS, Shirzadi Z, Swardfager W, Maclntosh BJ, Schultz A, Yang HS, et al. Amyloid-beta burden predicts prospective decline in body mass index in clinically normal adults. Neurobiol Aging. 2020;93:124-30. https://doi.org/1 0.1016/j.neurobiolaging.2020.03.002.

24. Ishii M, Wang G, Racchumi G, Dyke JP, ladecola C. Transgenic mice overexpressing amyloid precursor protein exhibit early metabolic deficits and a pathologically low leptin state associated with hypothalamic dysfunction in arcuate neuropeptide Y neurons. J Neurosci. 2014;34(27): 9096-106. https://doi.org/10.1523/JNEUROSCl.0872-14.2014.

25. Jimenez A, Pegueroles J, Carmona-Iragui M, Vilaplana E, Montal V, Alcolea D, et al. Weight loss in the healthy elderly might be a non-cognitive sign of preclinical Alzheimer's disease. Oncotarget. 2017;8(62):104706-16. https:// doi.org/10.18632/oncotarget.22218.

26. Hsu DC, Mormino EC, Schultz AP, Amariglio RE, Donovan NJ, Rentz DM, et al. Lower late-life body-mass index is associated with higher cortical amyloid burden in clinically normal elderly. J Alzheimers Dis. 2016;53(3): 1097-105. https://doi.org/10.3233/JAD-150987.

27. Kivimaki M, Luukkonen R, Batty GD, Ferrie JE, Pentti J, Nyberg ST, et al. Body mass index and risk of dementia: analysis of individual-level data from 1.3 million individuals. Alzheimer's Dement. 2018;14(5):601-9. https://doi.org/1 0.1016/j.jalz.2017.09.016.

28. Gottesman RF, Schneider AL, Zhou Y, Coresh J, Green E, Gupta N, et al. Association between midlife vascular risk factors and estimated brain amyloid deposition. Jama. 2017;317(14):1443-50. https://doi.org/10.1001/ja ma.2017.3090.

29. Vemuri P, Knopman DS, Lesnick TG, Przybelski SA, Mielke MM, Graff-Radford $J$, et al. Evaluation of amyloid protective factors and Alzheimer disease neurodegeneration protective factors in elderly individuals. JAMA Neurol. 2017;74(6):718-26. https://doi.org/10.1001/jamaneurol.2017.0244.

30. Chuang YF, An Y, Bilgel M, Wong DF, Troncoso JC, O'Brien RJ, et al. Midlife adiposity predicts earlier onset of Alzheimer's dementia, neuropathology and presymptomatic cerebral amyloid accumulation. Mol Psychiatry. 2016; 21(7):910-5. https://doi.org/10.1038/mp.2015.129.

31. Elsworthy RJ, Aldred S. The effect of age and obesity on platelet amyloid precursor protein processing and plasma markers of oxidative stress and inflammation. Exp Gerontol. 2020;132:110838. https://doi.org/10.1016/j. exger.2020.110838

32. Yaffe K, Kanaya A, Lindquist $K$, Simonsick EM, Harris T, Shorr Rl, et al. The metabolic syndrome, inflammation, and risk of cognitive decline. Jama. 2004;292(18):2237-42. https://doi.org/10.1001/jama.292.18.2237.

33. Carvalho A, Rea IM, Parimon T, Cusack BJ. Physical activity and cognitive function in individuals over 60 years of age: a systematic review. Clin Interv Aging. 2014;9:661-82. https://doi.org/10.2147/CIA.S55520.

34. Larson EB, Wang L, Bowen JD, McCormick WC, Teri L, Crane P, et al. Exercise is associated with reduced risk for incident dementia among persons 65 years of age and older. Ann Intern Med. 2006;144(2):73-81. https://doi.org/1 0.7326/0003-4819-144-2-200601170-00004.

35. Jia R-X, Liang J-H, Xu Y, Wang Y-Q. Effects of physical activity and exercise on the cognitive function of patients with Alzheimer disease: a metaanalysis. BMC Geriatr. 2019;19(1):181.

36. Kojima G, Taniguchi Y, lliffe S, Walters K. Frailty as a predictor of Alzheimer disease, vascular dementia, and all dementia among community-dwelling older people: a systematic review and meta-analysis. J Am Med Dir Assoc. 2016;17(10):881-8. https://doi.org/10.1016/j.jamda.2016.05.013.

\section{Publisher's Note}

Springer Nature remains neutral with regard to jurisdictional claims in published maps and institutional affiliations. 